\title{
Different scale land subsidence and ground fissure monitoring with multiple InSAR techniques over Fenwei basin, China
}

\author{
C. Zhao ${ }^{1,2}$, Q. Zhang ${ }^{1,2}$, C. Yang ${ }^{1,2}$, J. Zhang ${ }^{1,2}$, W. Zhu ${ }^{1,2}$, F. Qu ${ }^{1}$, and Y. Liu ${ }^{1}$ \\ ${ }^{1}$ College of Geology Engineering and Geomatics, Chang'an University, Xian Shaanxi, China \\ ${ }^{2}$ Key Laboratory of Western China's Mineral Resources and Geological Engineering, Ministry of Education, \\ No. 126 Yanta Road, Xian, Shaanxi, China \\ Correspondence to: C. Zhao (zhaochaoying@163.com) \\ Published: 12 November 2015
}

\begin{abstract}
Fenwei basin, China, composed by several sub-basins, has been suffering severe geo-hazards in last 60 years, including large scale land subsidence and small scale ground fissure, which caused serious infrastructure damages and property losses. In this paper, we apply different InSAR techniques with different SAR data to monitor these hazards. Firstly, combined small baseline subset (SBAS) InSAR method and persistent scatterers (PS) InSAR method is used to multi-track Envisat ASAR data to retrieve the large scale land subsidence covering entire Fenwei basin, from which different land subsidence magnitudes are analyzed of different sub-basins. Secondly, PS-InSAR method is used to monitor the small scale ground fissure deformation in Yuncheng basin, where different spatial deformation gradient can be clearly discovered. Lastly, different track SAR data are contributed to retrieve two-dimensional deformation in both land subsidence and ground fissure region, Xi' an, China, which can be benefitial to explain the occurrence of ground fissure and the correlation between land subsidence and ground fissure.
\end{abstract}

\section{Introduction}

Fenwei basin, composed by Fenhe basin in Shanxi province and Weihe basin in Shaanxi province, Northwest China, is located in the complex intersection of Ordos block, North China block and South China block. S-shaped Fenwei basin with $1200 \mathrm{~km}$ in length and 30 to $60 \mathrm{~km}$ in width, can be segmented into Datong, Xinzhou, Taiyuan, Linfen, Yuncheng, and Weihe six sub-basins from north to south. Approximate North-North-East faults control the hazard activies of each sub-basins.

Due to the frequent fault activities and complex geotectonics in this region, severe land subsidence and ground fissures have been occurred for around 60 years. Statistics show around 170 locations and 400 ground fissures have been detected in 56 counties within Fenwei basin. Besides, Fenwei basin is one of the three largest and severest land subsience regions in China. Consquently, great econmic losses and infrastracture damages have been caused in this basin.
So different InSAR techniques are employed to monitor the large scale land subsidence and small scale ground fissure deformation in Fenwei basin.

\section{Methodologies}

\subsection{PS-InSAR technique}

PS-InSAR successfully overcomes the problems of temporal and spatial decorrelation and heterogeneous atmospheric delay, which are main shortage in the conventional differential InSAR processing.

In this paper, we apply StaMPS-InSAR software for SAR data processing to achieve deformation results. The key steps are summarized as follows. Readers can refer to the papers as Hooper et al. (2004, 2007), Hooper (2006) and StaMPS software manual if they are interested in the details.

Suppose $N$ interferograms are generated from $N+1$ SAR images acquired at different epochs on the same track and 
same study area. The master image is selected by considering both temporal, spatial baseline and the influence of the Doppler central frequency (Hooper et al., 2007; Zebker and Villaseno, 1992). Usually, the master image minimizes the sum decorrelation of all the interferograms. The external digital elevation model (DEM), such as Shuttle radar topography mission (SRTM) DEM is used to remove the effects of topography. From the coregistered SAR SLC images and DEM subtracted interferograms, PS points below amplitude dispersion and phase stability thresholds are determined.

The following steps are only focused on these PS pixels. For a generic $i$-interferogram, the wrapped differential interferometric phase of a PS pixel $x$ can be described as:

$$
\begin{aligned}
\psi_{\mathrm{int}, x, i} & =W\left\{\varphi_{\text {def }, x, i}+\varphi_{\mathrm{atm}, x, i}+\Delta \varphi_{\mathrm{orb}, x, i}+\Delta \varphi_{\theta, x, i}\right. \\
& \left.+\varphi_{\mathrm{n}, x, i}\right\}
\end{aligned}
$$

where, $W\{\cdot\}$ indicates modulo $2 \pi$ radian operation, $\varphi_{\text {def }, x, i}$ is the phase change due to surface movement in line-ofsight direction, which is the mainly useful part for deformation analysis. While the other parts in Eq. (1) are nuisance terms, that is, $\Delta \varphi_{\theta, x, i}$ is the residual phase due to look angle error, $\varphi_{\mathrm{atm}, x, i}$ is the phase due to the difference in atmospheric delay between passes, $\Delta \varphi_{\mathrm{orb}, x, i}$ is the residual phase due to satellite orbit inaccuracies, $\varphi_{\mathrm{n}, x, i}$ is a noise term due to variability in scattering, thermal noise, co-registration errors and uncertainty in the position of the phase center in azimuth. Three dimensional phase unwrapping is applied to get more reliable unwrapping results (Hooper and Zebker, 2007). These nuisance terms can be well isolated by using low-pass filter in spatial domain and high-pass filter in time domain. Moreover, low-pass filter in time domain within a given Gaussian width can also recover the nonlinear deformation phase. Then annual deformation rate and time-series results can be trivially constructed.

\subsection{Combined PS and SBAS-InSAR technique}

Standard SB methods (Berardino et al., 2002; Lanari et al., 2004) work with interferograms that are first multilooked and then individually phase unwrapped. While in order to maitain highest possible resolution, Hooper (2008) refered to slowly decorrelating filtered phase (SDFP) pixels as the targets of SBAS methods. That is pixels whose phase when filtered decorrelates little over short time intervals are SDFP. The SBAS interferograms are formed by recombination of the resampled SLC images meeting both spatial and temporal baseline thresholds. First filtering in azimuth to exclude non-overlapping Doppler spectrum and in range to reduce the effects of geometric decorrelation. The geometric phase to be subtracted for each small baseline interferogram is calculated as the difference between the relevant single-master interferograms for both the flat-Earth and topographic phase.

SDFP pixels are identified among the candidate pixels in the same way that PS pixels are, using the algorithm of
Hooper et al. (2007). Then SDFP and PS are combined to maximize the reliability of the unwrapped phase. The unwrapped phase of the SB interferograms is inverted to derive a time series of phase change for each pixel in a least square fashion because of only one SBAS dataset is considered.

\subsection{Two dimensional deformation with ascending and descending data}

Because both InSAR ascending and descending data are from near-polar orbits, which makes it not sensitive to the deformation field in the north-south direction (Wright et al., 2004; Samsonov et al., 2006; Jung et al., 2011). Thus the deformation components in the east-west and vertical directions are estimated by fusing the descending and ascending InSAR Line-of-sight displacements. The measurement equations can be written as:

$\left[\begin{array}{c}v_{\mathrm{e}} \\ v_{\mathrm{u}}\end{array}\right]=\mathbf{U} \cdot\left[\begin{array}{c}d_{\mathrm{e}} \\ d_{\mathrm{u}}\end{array}\right]-R_{\mathrm{los}}$

where $\boldsymbol{d}=\left(d_{\mathrm{e}}, d_{\mathrm{u}}\right)^{T}$ is the 2-dimensional deformation vector (east, up) in a local reference frame; $\mathbf{U}$ is a matrix consisting of $\operatorname{LOS}$ vectors $(\sin \theta \cdot \cos \phi, \cos \theta)$, where $\theta$ is the radar incidence angle and $\varphi$ is the satellite heading angle; $R_{\text {los }}$ represents the LOS measurement, and $\left(v_{\mathrm{e}}\right.$, $v_{\mathrm{u}}$ ) is the observation residual. By minimizing the observation residual with least square norm, the deformation vector $\boldsymbol{d}=-\left(U^{T} \cdot U\right)^{-1} \cdot U^{T} \cdot R_{\mathrm{los}}$ is obtained.

\section{Data}

In total 74 archived C-band Envisat ASAR data acquired from 2006 to 2010 from seven descending tracks and $22 \mathrm{~L}-$ band ascending ALOS PALSAR data covering part of Weihe basin are employed to monitor the large scale land subsidence and small scale ground fissure deformation (Fig. 1).

\section{Results}

\subsection{Large scale land subsidence deformation}

\subsubsection{Fenwei basin}

The combined PS and SBAS technique is applied to calculate the entire Fenwei basin land subsidence with $67000 \mathrm{~km}^{2}$. The annual land subsidence rate map in entire Fenwei basin is shown in Fig. 2, from which the land subsidence area is up to $42000 \mathrm{~km}^{2}$. The maximum subsidence rates in different sub-basins range from $2 \mathrm{~cm} \mathrm{yr}^{-1}$ to over $10 \mathrm{~cm} \mathrm{yr}^{-1}$, while the area with subsidence rate larger than $2 \mathrm{~cm} \mathrm{yr}^{-1}$ is around $2000 \mathrm{~km}^{2}$. Besides, high speed railway connecting Datong in the north of Shanxi province and Xian, capital of Shaanxi province is designed inevitablely to pass through land subsidence regions. As shown in Fig. 3 the maximum land subsidence rate presented in Qixian, Taiyuan basin was up to 


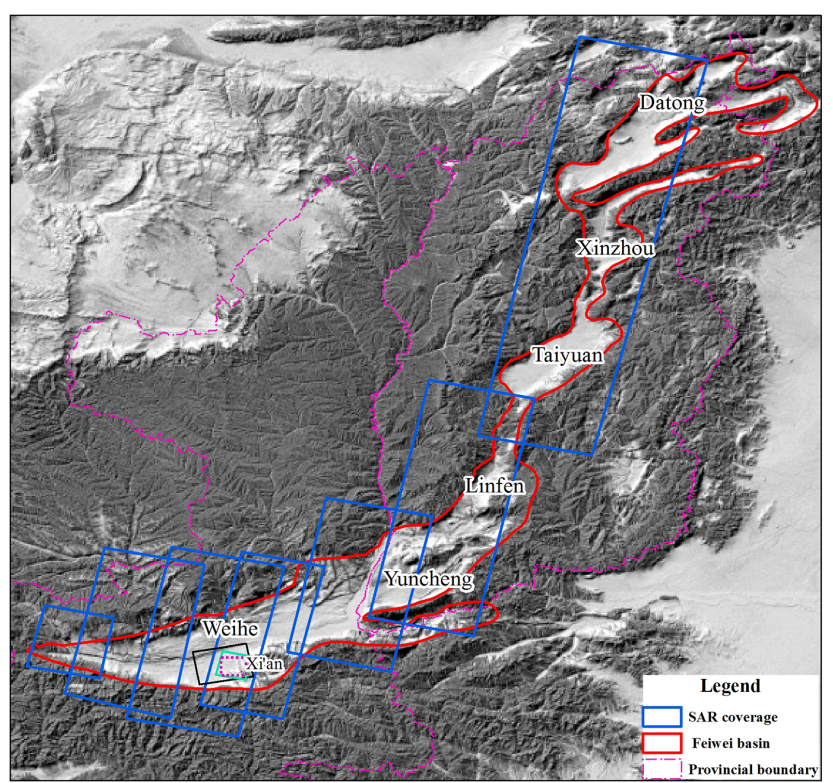

Figure 1. SAR coverage sketch map of Fenwei basin.

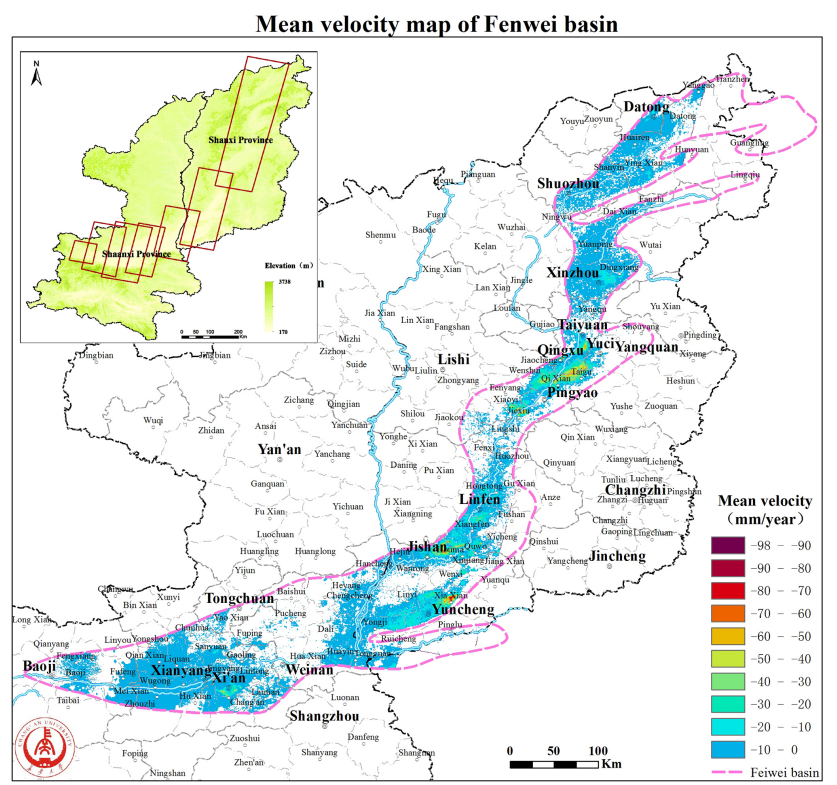

Figure 2. Annual land subsidence rate map in entire Fenwei basin.

$6 \mathrm{~cm} \mathrm{yr}^{-1}$, accordingly, the design had altered from ballastless track on bridge to ballast track on fundation (see inset photo of Fig. 3).

\subsubsection{Taiyuan basin}

Taiyuan basin is one of the severest deformation regions in Fenwei basin, closely check in Fig. 4, we can see that the land subsidence in Taiyuan basin is controlled by the normal faults surrounding the basin. Seven counties, including Taiyuan, Qingxu, Jiaocheng, Qixian, Taigu, Wenshui and Jiexiu, are

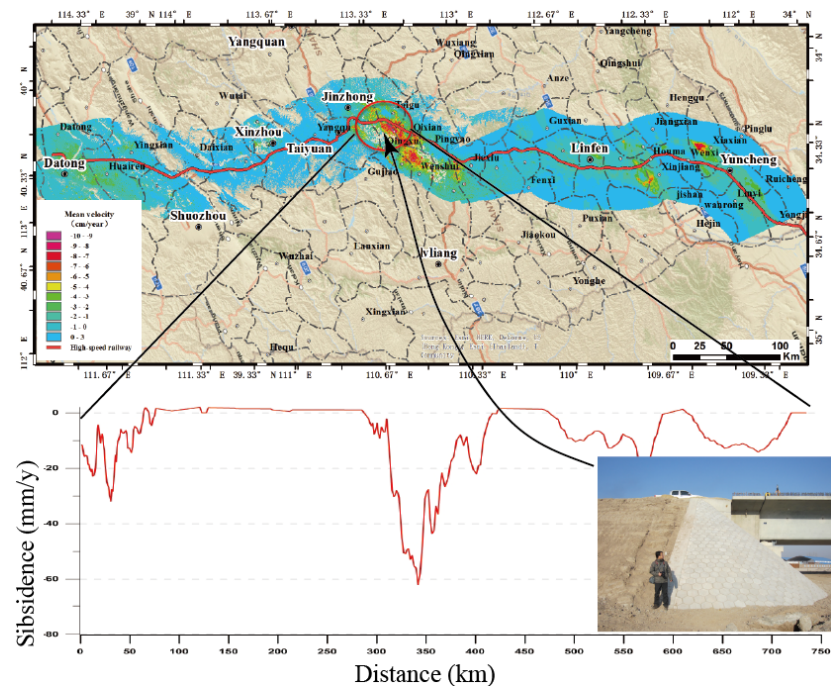

Figure 3. Deformation map along Datong-Yuncheng high speed railway (HSR). Insets are land subsidence profile in Qixian county and field photo of joint of bridge and foundation of HSR under construction.

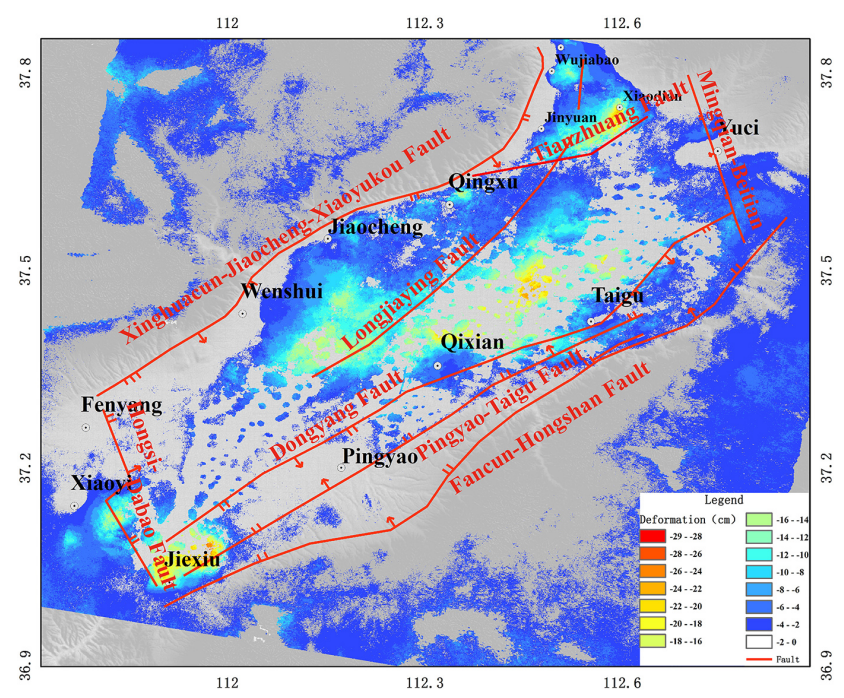

Figure 4. Land subsidence map over Taiyuan basin.

sufferring from obvious land subsidence. Moreover, some counties have also been affected by the ground fissures deformation.

\subsection{Small scale ground fissure deformation}

\subsubsection{Yuncheng basin}

Xia county in Yuncheng basin has been suffering ground fissures hazard for several years. Figure 5 is the annual deformation map calculated from Envisat data during 2008 to 2010. It is clearly to see the normal fault Zhongtiaoshan controls the deformation region. And different deformation mag- 


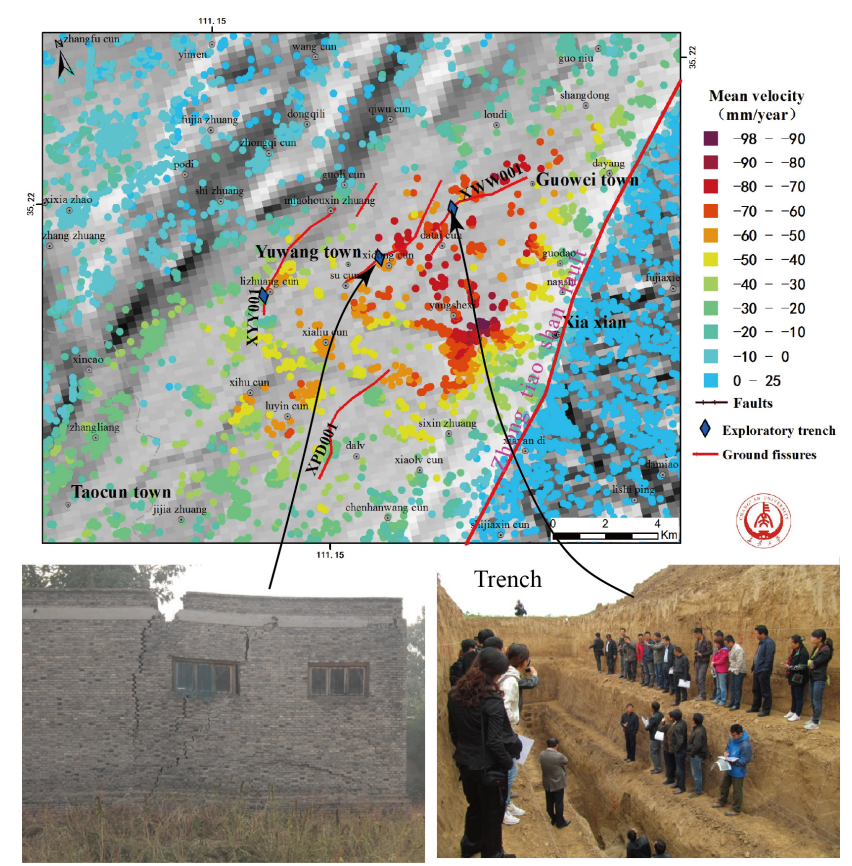

Figure 5. Ground fissure deformation map in Xia County, Yuncheng basin.

nitudes can be monitored in the two sides of each ground fissures. Inset photos show the trench of one fissure, which emerged in 2000, and had around $20 \mathrm{~cm}$ surface dislocation and $10 \mathrm{~cm}$ opening width (Liu, 2014). The maximum land subsidence occurred close to the Zhongtiaoshan normal fault with maximum subsidence rate around $10 \mathrm{~cm} \mathrm{yr}^{-1}$.

\subsubsection{Xian city}

Up-to-date, in total 14 ground fissures have been occurred in Xian city, which affect the areas of around $250 \mathrm{~km}^{2}$. Therefore special measures of the constructions in this region must be taken to mitigate the influence of ground fissures movements.

The 2-D deformation components are shown in Fig. 6. The vertical displacements (Fig. 6b) range between -110 and $20 \mathrm{~mm}$, which are much larger than the east-west motions (Fig. 6a). This confirms that the vertical motion dominates the deformation field in Xian. Areas with larger east-west displacements correspond to regions of larger vertical displacements where active ground fissures are present (Fig. 6). Horizontal displacements cannot be ignored in land subsidence measurement when the deformation is large, particularly when ground fissures are active (Qu et al., 2014).

\section{Conclusions}

Multiple InSAR techniques, including combined SBAS and PS-InSAR, two-dimensional inversion from ascending and descending are employed to large scale land subsidence and
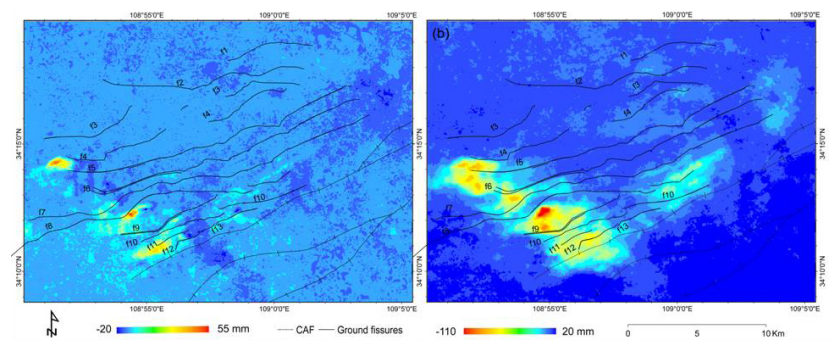

Figure 6. 2-D deformation map in 2009 by using ascending ALOS and descending Envisat ASAR data, whose coverages are marked on Fig. 1 in pink dash line: (a) the east-west component of the deformation field; (b) the vertical component of the deformation field.

small scale ground fissure deformation calculation. High accuracy InSAR results can not only show different magnitude land subsidence in different sub-basins, but also the different deformation gradient and direction crossing localized ground fissures. The results have been and will be refer to the engineering design and construction in order to mitigate the damage and losses. While, high resolution SAR data will be considered to monitor the up-to-date deformation and fine deformation features regarding small scale fissures.

Acknowledgements. This research is funded by projects of the Natural Science Foundation of China (NSFC) (No. 41372375, 41274005 and 41202245), and the project of the Ministry of Land \& Resources, China (No. 1212011220186). Three arcseconds SRTM DEM are freely downloaded from the website http://rmw.recordist.com/index.html. StamPS package is freely downloaded from the website http://homepages.see.leeds.ac.uk/ earahoo/stamps/index.html. The archived Envisat ASAR data are provided by ESA Category 1 project.

\section{References}

Berardino, F., Fornaro, G., Lanari, R., and Sansosti, E.: A new algorithm for surface deformation monitoring based on small baseline differential SAR interferometry, IEEE T. Geosci. Remote, 40, 2375-2383, 2002.

Hooper, A.: Persistent Scaterrer Radar Interferometry for Crustal Deformation Studies and Modeling of Volcanic Deformation, $\mathrm{PhD}$ thesis, Stanford University, Palo Alto, 2006.

Hooper, A.: A multi-temporal InSAR method incorporating both persistent scatterer and small baseline approaches, Geophys. Res. Lett., 35, L16302, doi:10.1029/2008GL034654, 2008.

Hooper, A. and Zebker, H.: Phase unwrapping in three dimensions with application to InSAR time series, J. Opt. Soc. Am. A, 24, 2737-2747, 2007.

Hooper, A., Zebker, H., Segall, P., and Kampes, B.: A new method for measuring deformation on volcanoes and other natural terrains using InSAR persistent scatterers, Geophys. Res. Lett., 31, 611-615, 2004.

Hooper, A., Segall, P., and Zebker, H.: Persistent scatterer InSAR for crustal deformation analysis, with application to 
Volcán Alcedo, Galapagos, J. Gephys. Res., 112, B07407, doi:10.1029/2006JB004763, 2007.

Jung, H. S., Lu, Z., Won, J., Poland, M., and Miklius, A.: Mapping three-dimensional surface deformation by combining multiple aperture interferometry and conventional interferometry: application to the June 2007 eruption of Kîlauea Volcano, Hawaii, IEEE Geosci. Remote Sens. Lett., 8, 34-38, 2011.

Lanari, R., Mora, O., Mununta, M., Mallorqui, J., Berardino, P., and Sansonsti, E.: A Small Baseline Approach for Investigating Deformation on Full resolution Differential SAR Interferograms, IEEE T. Geosci. Remote, 42, 1377-1386, 2004.

Liu, Y.: The Study on the Mass Mechanism of Ground Fissures in Piedmont Fault on the Plate-Case of Yuncheng Basin Xiaxian Ground Fissures, master thesis, Chang'an University, Xi'an, 2014.
Qu, F., Zhang, Q., Lu, Z., Zhao, C., Yang, C., and Zhang, J.: Land subsidence and ground fissures in Xi'an, China 2005-2012 revealed by multi-band InSAR time-series analysis, Remote Sens. Environ., 155, 366-376, 2014.

Samsonov, S. and Tiampo, K.: Analytical optimization of DInSAR and GPS dataset for derivation of three-dimensional surface motion, IEEE Geosci. Remote Sens. Lett., 3, 107-111, 2006.

Wright, T. J., Parsons, B. E., and Lu, Z.: Toward mapping surface deformation in three dimensions using InSAR, Geophys. Res. Lett., 31, L01607, doi:10.1029/2003GL018827, 2004.

Zebker, H. A. and Villaseno, J.: Decorrelation in interferometric radar echoes, IEEE T. Geosci. Remote, 30, 950-959, 1992. 